TITLE:

\title{
A successful attempt to prevent postoperative adhesions between the mediastinum and a lung: a canine model.
}

\section{$\operatorname{AUTHOR}(S):$}

Hamaji, Masatsugu; Nakamura, Tatsuo

\section{CITATION:}

Hamaji, Masatsugu ...[et al]. A successful attempt to prevent postoperative adhesions between the mediastinum and a lung: a canine model.. General thoracic and cardiovascular surgery 2015, 63(8): 483-484

ISSUE DATE:

2015-05-23

URL:

http://hdl.handle.net/2433/201949

\section{RIGHT:}

The final publication is available at Springer via http://dx.doi.org/10.1007/s11748-015-0563-6.; The full-text file will be made open to the public on 23 May 2016 in accordance with publisher's 'Terms and Conditions for Self-Archiving':; This is not the published version. Please cite only the published version.; この論文は出版社版でありません。引用の際には 出版社版をご確認ご利用ください。 
A successful attempt to prevent postoperative adhesions between the mediastinum and a lung: a canine model

Masatsugu Hamaji, M.D., Tatsuo Nakamura, M.D., PhD

Department of Bioartificial Organs, Institute for Frontier Medical Sciences, Kyoto University

* Corresponding author:

Masatsugu Hamaji, MD

Department of Bioartificial Organs, Institute for Frontier Medical Sciences, Kyoto University, 53

Kawaharacho, Shogoin, Sakyo-ku, Kyoto, 606-8507, Japan.

Ph: +81-75-751-4149

Fax: +81-75-751-4844

E-mail address: mhamaji@kuhp.kyoto-u.ac.jp

Key words; thoracotomy, adhesion, mediastinum, lung 


\section{$\underline{\text { Abstract }}$}

After right-sided mediastinal pleurectomies, a bioabsorbable sheet was sutured to cover the pleurectomy defect $(\mathrm{N}=5)$, whereas not in a control $(\mathrm{N}=4)$. There was a significant difference in the mediastinal adhesion between the groups. Our findings suggested the sheet may prevent postoperative adhesions between the mediastinum and a lung.

Previously we reported an anti-adhesive effect of a bioabsorbable sheet between the chest wall and a lung [1]. In this study, we aimed to investigate whether the sheet may prevent adhesions between the mediastinum and a lung in a canine model since postoperative adhesions between those and may affect adversely re-operative pulmonary resections [2].

Seamdura ${ }^{\circledR}$ is a bioabsorbable sheet [1], composed of poly-L-lactide copolymer and $\varepsilon$-caprolactone, and polyglycolic acid. Nine adult beagle dogs underwent a right thoracotomy and an upper mediastinal pleurectomy $(2 \mathrm{~cm} \times 3 \mathrm{~cm})$ (Figure a). In the experimental $(\mathrm{N}=5)$, a $3 \mathrm{~cm} \times 5 \mathrm{~cm}$ sheet was sutured on the pleura with of 4-0 polydiaxanone (Figure b) to cover the defect, while not in the control $(\mathrm{N}=4)$. At 1 month, mediastinal adhesions were observed in all the control (Figure c) and 1 of the experimental group ( $\mathrm{p}=0.048$, by Fisher's exact test). Four of the experimental did not show a mediastinal adhesion (Figure d) with the sheet almost intact and the pleural layer regenerated (Figure e). The procedures were performed in accordance with the "Guide for the Care and Use of Laboratory Animals" published by the National Institutes of Health (NIH Publication No. 85-23, revised 1985).

Our findings suggest the bioabsorbable sheet may prevent mediastinal adhesions with a lung, which 
can be challenging a risk factor of conversion of thoracoscopic surgery to open thoracotomy at re-operative procedures [2]. 


\section{$\underline{\text { References }}$}

[1] Hamaji M, Kojima F, Komatsu T, Tsuruyama T, Date H, Nakamura T. A synthetic bioabsorbable sheet

may prevent postoperative intra-pleural adhesions following thoracotomy: a canine model. Interact

Cardiovasc Thorac Surg. 2014;19:914-20

[2] Hamaji M, Cassivi SD, Shen KR, Allen MS, Nichols FC, Deschamps C, et al. Prior thoracoscopic surgery may improve reoperative pulmonary resection. Asian Cardiovasc Thorac Ann. 2013;22:700-705 


\section{Figure legends}

After a right-sided upper mediastinal pleurectomy (a), the bioabsorbable sheet was sutured on the mediastinal pleura to cover the defect (b) in the experimental group. Adhesions were formed in all the control (c). № adhesion in 4 of the experimental with the mediastinal pleura regenerated macroscopically (d) and microscopically (e, hematoxylin and eosin staining, $\times 10)$. 
